\title{
REPOSIÇÃO DE IMUNOGLOBULINA HUMANA EM PACIENTES PEDIÁTRICOS DE UM HOSPITAL TERCIÁRIO
}

Pôster

Autores deste trabalho:

LIGIA SPAGNOL RANALLI: HOSPITAL INFANTIL SABARA/ INSTITUTO PENSI

FATIMA RODRIGUES FERNANDES: HOSPITAL INFANTIL SABARA/ INSTITUTO PENSI

ALESSANDRA MIRAMONTES LIMA: HOSPITAL INFANTIL SABARA/ INSTITUTO PENSI

CHAYANNE ANDRADE DE ARAUJO: HOSPITAL INFANTIL SABARA/ INSTITUTO PENSI

MARILISE GUEDES CANDIDO LANDO: HOSPITAL INFANTIL SABARA/ INSTITUTO PENSI

Área do Trabalho: Pediatria

Data da submissão: 09/08/2018 às 22:11

\section{Justificativa}

Promover aumento de Imunoglobulina da classe IgG

\section{Objetivo(s)}

Avaliação dos resultados da reposição de Imunoglobulina Humana por via intravenosa e subcutânea, nos pacientes em seguimento em hospital pediátrico terciário.

\section{Método(s)}

Estudo retrospectivo, com análise de prontuários de pacientes que realizaram avaliação imunológica, no período de janeiro de 2014 a junho de 2018.

\section{Resultado(s)}

Desde a implantação da cobertura hospitalar pela equipe de imunologia, tivemos em média 25 avaliações por mês, em particular, de pacientes com infecções graves, de repetição ou associadas a síndromes. Neste estudo, analisamos vinte e quatro pacientes nos quais constatamos hipogamaglobulinemia, 18 (72\%) do gênero masculino, nos quais houve a indicação de reposição de imunoglobulina humana. A idade de início da reposição variou de 2 meses a 10 anos e os diagnósticos encontrados foram: Hipogamaglobulinemia transitória da infância (7 casos, 29\%), SCID (4 casos, 16,7\%), Síndrome de Down (4 casos, 16,7\%), Deficiência de anticorpos não classificadas (3 casos, 12,5\%), Agamaglobulinemia ligada ao X (1 caso, 4,2\%), Síndrome de HiperlgM (1 caso, 4,2\%), Síndrome de Di George (1 caso, 4,2\%), associação com síndromes genéticas - VACTERL ( 1 caso, 4,2\%), Silver Russel (1 caso, 4,2\%) e Distúrbio de Glicosilação tipo $1 \mathrm{~A}$ (1 caso, 4,2\%). Destes, onze casos (45,8\%) receberam reposição de Imunoglobulina Intravenosa (IGIV), com doses entre 400$600 \mathrm{mg} / \mathrm{kg} / \mathrm{mês}$ e doze (50\%) fizeram reposição com Imunoglobulina Subcutânea (IGSC), na dose de $200 \mathrm{mg} / \mathrm{kg}$ quinzenal. A escolha pela via subcutânea foi feita pela 


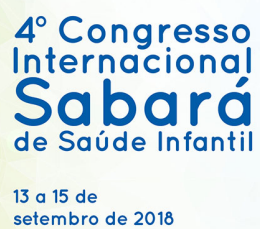

$4^{\circ}$ Congresso Internacional

de Saúde Infantil

setembro de 2018
Hotel Maksoud Plaza
Alameda Campinas, 150
Säo Pavio-Brosil

dificuldade de acesso venoso em lactentes e não por eventos advsersos graves relacionados a infusão endovenosa. Os resultados foram satisfatórios com ambas as vias de administração e os pacientes mantinham nível sérico de Imunoglobulina $G$ acima do percentil 50 para a idade e menor índice de infecções. Apenas dois pacientes apresentaram reação adversa com IGIV.

\section{Conclusão (ões)}

A terapia de reposição de Imunoglobulina humana por via subcutânea e intravenosa, permitiu manutenção de valores satisfatórios de lgG sérica e estabilização clínica dos pacientes. Portanto, a via para reposição de imunoglobulina a ser escolhida deve ser individualizada, levando-se em conta efeitos colaterais e viabilidade de acesso venoso. Para esses casos especiais, contamos com via subcutânea, sendo uma opção segura e eficaz para a população pediátrica. 